\title{
Screening of environmental samples for bacteria producing 1,3-propanediol from glycerol
}

\author{
Sławomir Dąbrowski ${ }^{\varpi}$, Ewa Zabłotna, Dorota Pietrewicz-Kubicz and Anna Długołęcka \\ A\&A Biotechnology, Gdynia, Poland
}

\begin{abstract}
Twenty nine environmental samples were screened for the presence of anaerobic microorganisms fermenting glycerol with 1,3-propanediol as a final product. Seven samples were then selected for the next step of our research and eight bacteria strains were cultured anaerobically. Seven of them produced 1,3-propanediol with a yield of $0.47-0.58$. Six of the the isolated microorganisms were then classified as Clostridium butyricum (four strains), C. lituseburense (one strain), and C. sartagoforme (one strain). We suggest that of all these strains $C$. butyricum 2CR371.5 is the best 1,3-propanediol producer as producing no lactate as a by-product and growing well on a glycerol-containing medium.
\end{abstract}

Key words: 1,3-propanediol, anaerobic fermentation, biodiesel, Clostridium, glycerol, screening

Received: 12 February, 2012; revised: 16 July, 2012; accepted: 30 July, 2012; available on-line: 01 August, 2012

\section{INTRODUCTION}

The global biodiesel production was over 15 billion litres in 2009 and it is still increasing. The forecast for the worldwide production is over 45 billion litres in 2020 (GlobalData, 2010). As a by-product, $5-10 \%$ of crude glycerol is produced (Yazdani \& Gonzalez, 2007). The conversion of glycerol to higher-value products could be a way to decrease the cost of biofuel production.

1,3-propanediol (1,3-PDO) is one of the products obtainable from crude glycerol. The main application of 1,3-PDO is as a substrate in polymerization of polytrimethylene terephthalate (PTT), a type of polyester used in engineering thermoplastics and in the production of carpets and textile fibers (Liu et al., 2010).

Biological production of 1,3-propanediol is an alternative to chemical methods. Several bacterial species microorganisms able to ferment glycerol with 1,3-PDO as final product are known e.g. Lactobacillus hilgardii, Citrobacter freundii, Clostridium saccharobutylicum, Clostridium butyricum, Clostridium diolis and Klebsiella pneumoniae (Boenigk et al., 1993; Mu et al., 2006; Burkhard et al., 2009; Pasteris et al., 2009; Gungormusler et al., 2010; Chatzifragkou et al., 2011). Moreover, genetically modified E. coli strains can also be used (Emptage et al., 2009; Eliot et al., 2011).

Glycerol fermentation by the glycerol-fermenting microorganisms is a two-branched pathway. Production of 1,3-PDO is the reductive branch catalysed by two enzymes, (i) glycerol dehydratase and (ii) 1,3-PDO oxidoreductase, with 3-hydroxypropionaldehyde as an intermediate (Fig. 1). In the oxidative branch glycerol is dehydrogenated by glycerol dehydrogenase to dihydroxyacetone (DHA). DHA is then phosphorylated by ATP or phosphoenolpyruvate to dihydroxyacetone phosphate
(DHAP) which is an intermediate in pyruvate synthesis (Gupta et al., 2009).

Microorganisms belonging to the genus Clostridium may also produce acetate, butyrate, lactate, propionate, ethanol and butanol as by-products of glycerol fermentation. The presence and amount of these compounds differs depending on the fermentation conditions and the Clostridium species strain (Dabrock et al., 1992; Biebl et al., 2001; Taconi et al., 2010).

The aim of our research was to screen different environmental samples for the presence of microorganisms fermenting glycerol with 1,3-PDO as a final product.

\section{MATERIALS AND METHODS}

Environmental samples and bacterial strains. The environmental samples were the waste containing crude glycerol from biogas plants from Poland (PWiK Gdynia, Przechlewo), Denmark (Lintrup, Blahoj, Hashoj, Filskow, Vegger) or from the A\&A Biotechnology collection of environmental samples.

As the reference strains, Clostridium butyricum (DSMZ, DSM-2478), Clostridium lituseburense (DSMZ, DSM-797), and Clostridium sartagoforme (DSMZ, DSM-1292) were used.

Media and culture conditions. Mixed bacterial cultures, the newly isolated strains as well as the reference Clostridium sp. strains were cultured anaerobically at $37^{\circ} \mathrm{C}$, $53^{\circ} \mathrm{C}$ or $60^{\circ} \mathrm{C}$, for $4-7$ days. Media used in this study contained: Yeast Nitrogen Base without amino acids and without ammonium sulphate (Formedium) - $6.9 \mathrm{~g} \cdot \mathrm{l}^{-1}$, $\mathrm{NaHCO}_{3}-2.6 \mathrm{~g} \cdot \mathrm{l}^{-1}$, yeast extract $-2 \mathrm{~g} \cdot \mathrm{l}^{-1}$, glycerol - 10-30 g $\cdot \mathrm{l}^{-1}$, cysteine $-0.5 \mathrm{~g} \cdot \mathrm{l}^{-1}$, resazurin - 0.5 $\mathrm{mg} \cdot \mathrm{l}^{-1}, \mathrm{MgCl}_{2} \cdot 6 \mathrm{H}_{2} \mathrm{O}-0.9 \mathrm{~g} \cdot \mathrm{l}^{-1}, \mathrm{ZnCl}_{2}-50 \mathrm{ng} \cdot \mathrm{l}^{-1}$, $\mathrm{MnCl}_{2} \cdot \mathrm{H}_{2} \mathrm{O}$ - $38 \mathrm{~g} \cdot \mathrm{l}^{-1}, \mathrm{CoCl}_{2} \cdot 2 \mathrm{H}_{2} \mathrm{O}-50 \mathrm{ng} \cdot \mathrm{l}^{-1}$, $\mathrm{NiCl}_{2} \cdot 6 \mathrm{H}_{2} \mathrm{O}-92 \mathrm{ng} \cdot \mathrm{l}^{-1}, \mathrm{FeCl}_{2} \cdot 2 \mathrm{H}_{2} \mathrm{O}-2.3 \mathrm{mg} \cdot \mathrm{l}^{-1}$, $(\mathrm{NH})_{4} \mathrm{Mo}_{7} \mathrm{O}_{24} \cdot 4 \mathrm{H}_{2} \mathrm{O}-50 \mathrm{ng} \cdot \mathrm{l}^{-1}$, EDTA $-0.5 \mathrm{mg} \cdot \mathrm{l}^{-1}$. The solid media on Petri plates for the growth at $37^{\circ} \mathrm{C}$ were solidified with $20 \mathrm{~g} \cdot \mathrm{l}^{-1}$ of agar. An anaerobic atmosphere was generated by using Biogon ${ }^{\circledR}$ C-20 $(80 \%$ $\mathrm{N}_{2}, 20 \% \mathrm{CO}_{2}$ ). All experiments in anaerobic conditions were performed in a MiniMACS anaerobic workstation (Don Whitley Scientific).

Screening for 1,3-PDO-producing microorganisms. The sediments were mixed with the liquid medium containing $10 \mathrm{~g} \cdot \mathrm{l}^{-1}$ glycerol in a $1: 1$ ratio in a total vol-

\footnotetext{
e-mail: sd@aabiot.com
}

Accession numbers (GenBank): JQ248565 - strain 2ER371.1; JQ248566 - strain 2MR375.1; JQ248567 - strain 2NR375.1; JQ248568 - strain 2CR371.5; JQ248569 — strain 2DR37.1; JO248570 - strain 2DR37.2.

Abbreviations: 1,3-PDO- 1,3-propanediol; DSMZ- Leibnitz-Institut Deutsche Sammlung von Mikroorganizmen und Zellkulturen $\mathrm{GmbH}$ 
Table 1. Glycerol fermentation by bacterial strains isolated from environmental samples.

\begin{tabular}{|c|c|c|c|c|c|c|c|c|}
\hline \multirow{2}{*}{ Strain name } & \multirow{2}{*}{ Origin } & \multirow{2}{*}{$\begin{array}{l}16 S \text { rDNA } \\
\text { similarity }\end{array}$} & \multicolumn{6}{|c|}{ Yield [g per $1 \mathrm{~g}$ glycerol consumed] } \\
\hline & & & 1,3-PDO & Acetate & Butyrate & Lactate & Propionate & Ethanol \\
\hline 2CR371.5 & $A \& A$ & $\mathrm{Cb}$ & 0.570 & 0.019 & 0.160 & 0.000 & 0.045 & 0.000 \\
\hline 2NR371.5 & $A \& A$ & $\mathrm{Cb}$ & 0.580 & 0.002 & 0.134 & 0.047 & 0.046 & 0.000 \\
\hline 2DR37.1 & $A \& A$ & $\mathrm{Cb}$ & 0.500 & 0.000 & 0.142 & 0.008 & 0.049 & 0.000 \\
\hline 2DR37.2 & $A \& A$ & $\mathrm{Cb}$ & 0.480 & 0.000 & 0.136 & 0.008 & 0.050 & 0.000 \\
\hline $2 \mathrm{HS} 37.2$ & Vegger & $\mathrm{Cb}$ & 0.470 & 0.010 & 0.105 & 0.020 & 0.050 & 0.000 \\
\hline 2ER371.1 & Hashoj & $\mathrm{Cl}$ & 0.540 & 0.110 & 0.000 & 0.038 & 0.049 & 0.117 \\
\hline 2MS37.4 & Przechlewo & $\mathrm{Cb}$ & 0.580 & 0.007 & 0.000 & 0.000 & 0.052 & 0.008 \\
\hline 2MR375.1 & Przechlewo & Cs & 0.000 & 0.000 & 0.000 & 0.000 & 0.560 & 0.120 \\
\hline Cb DSM 2478 & DSMZ & & 0.368 & 0.000 & 0.090 & 0.107 & 0.208 & 0.000 \\
\hline CI DSM 797 & DSMZ & & 0.342 & 0.100 & 0.000 & 0.015 & 0.030 & 0.005 \\
\hline Cs DSM 1292 & DSMZ & & 0.000 & 0.000 & 0.000 & 0.010 & 0.000 & 0.005 \\
\hline
\end{tabular}

$\mathrm{Cb}$, Clostridium butyricum; Cl, Clostridium lituseburense; Cs, Clostridium sartagoforme.

ume of $100 \mathrm{ml}$. They were cultivated at $37^{\circ} \mathrm{C}, 53^{\circ} \mathrm{C}$ or $60^{\circ} \mathrm{C}$ for $4-7$ days and then were analysed using HPLC. Samples in which 1,3-PDO production was observed were then used for inoculation (in a ratio of $1: 10$ ) of the liquid medium containing $30 \mathrm{~g} \cdot \mathrm{l}^{-1}$ glycerol and cultured in the total volume of 11 as described above. The mixed cultures were then cultivated on solid medium and single colonies were used for culturing on liquid medium with glycerol. To ensure that single strain cultures were obtained culturing on solid and liquid medium was repeated. At each step a HPLC analysis was performed for the presence of 1,3-PDO and glycerol. The yield of 1,3PDO production was calculated as g 1,3-PDO per $1 \mathrm{~g}$ of consumed glycerol.

Phylogenetic analysis. Phylogenetic analyses were performed by alignment of $16 \mathrm{~S}$ rDNA sequence fragments. To amplify the $16 \mathrm{~S}$ rDNA fragments universal DNA primers FD1F: 5'-GAGTTTGATCCTGGCTCAG-3' and RP2: 5'-ACGGCTACCT'TGT'TAC-

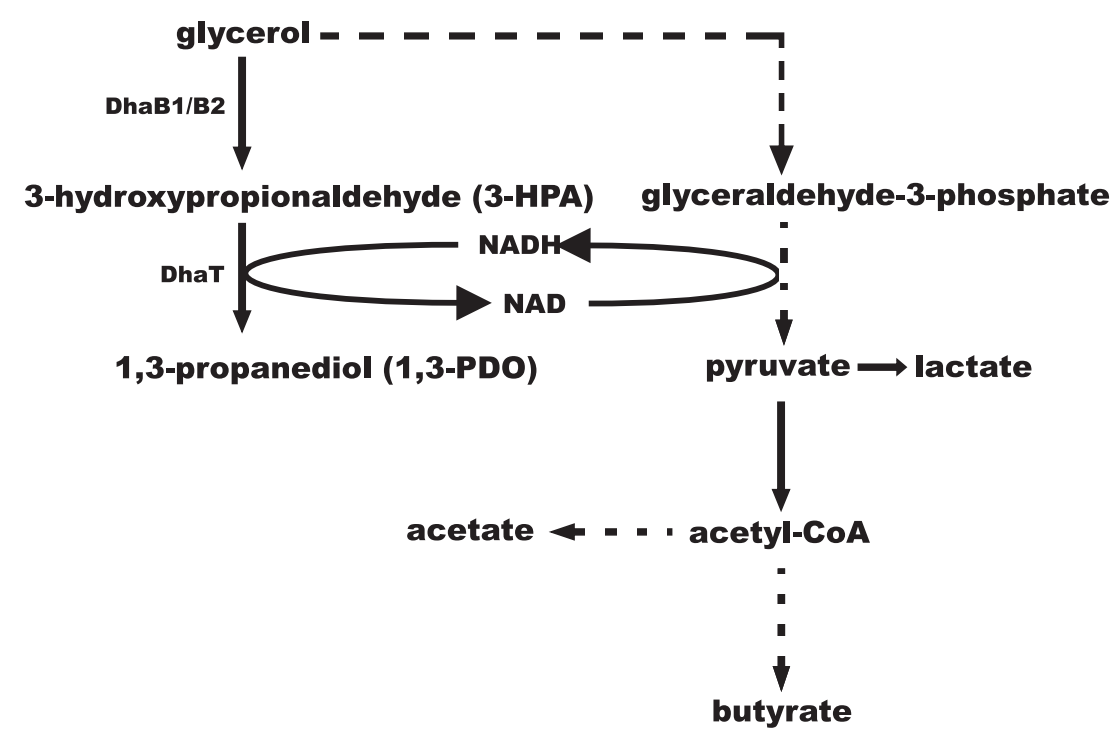

Figure 1. Glycerol fermentation pathway in anaerobic microorganisms.

Dashed lines indicate multiple steps. DhaB1, glycerol dehydratase; DhaB2, glycerol dehydratase activator; DhaT, NADH-dependent 1,3-propanediol oxidoreductase.
GACT'T-3' (Weisburg et al., 1991) were used. The PCR products were then purified with Clean-up AX kit (A\&A Biotechnology), sequenced (Macrogen), and compared with the sequences deposited in the GenBank using BLAST program. A phylogenetic tree was constructed using the sequence distance method and the neighbour joining algorithm (Saitou \& Nei, 1987) by use of Vector NTI software (InforMax).

HPLC analysis. HPLC analyses were performed using a HPLC Agilent 1200 Series system with RID and DAD detectors, a Phenomenex Rezex ROA column $\left(300 \times 7.80 \mathrm{~mm} ; 8\right.$ microns) with a $3 \mathrm{mM} \mathrm{H}_{2} \mathrm{SO}_{4}$ as the eluent $\left(0.6 \mathrm{ml} \cdot \mathrm{min}^{-1}\right)$ and the column temperature of $60^{\circ} \mathrm{C}$. Glycerol, 1,3-PDO, butyrate, acetate, lactate, propionate, formic acid, ethanol, 1-butanol, and acetone in culture media were analysed.

GC analysis. GC analysis was performed using a MLGC82, MicrolabAarhus. Fermentation gases, $\mathrm{CO}_{2}$ and $\mathrm{H}_{2}$ were separated on Hayesep Q column, 80/100 mesh, $1.5 \mathrm{~m} \times 1.4 \mathrm{Cu}$ med, with $\mathrm{N}_{2}$ as the carrier gas.

\section{RESULTS}

At the first step of our research 29 biological samples from biogas plants and A\&A Biotechnology collection of environmental samples were tested. After 4-7 days at $37^{\circ} \mathrm{C}$ bacterial growth was observed for all the analysed samples. At $53^{\circ} \mathrm{C}$ and $60^{\circ} \mathrm{C}$ only few samples contained microorganisms able to grow anaerobically at these conditions (data not shown). The anaerobic cultures of these samples were then analysed by HPLC for the presence and concentrations of glycerol, 1,3-PDO, lactate, butyrate, and acetate. We were looking for samples fermenting glycerol to 1,3-PDO with only low concentration of the other analysed chemicals. The best results were obtained for the samples cultured at $37^{\circ} \mathrm{C}$ (Fig. 2). 


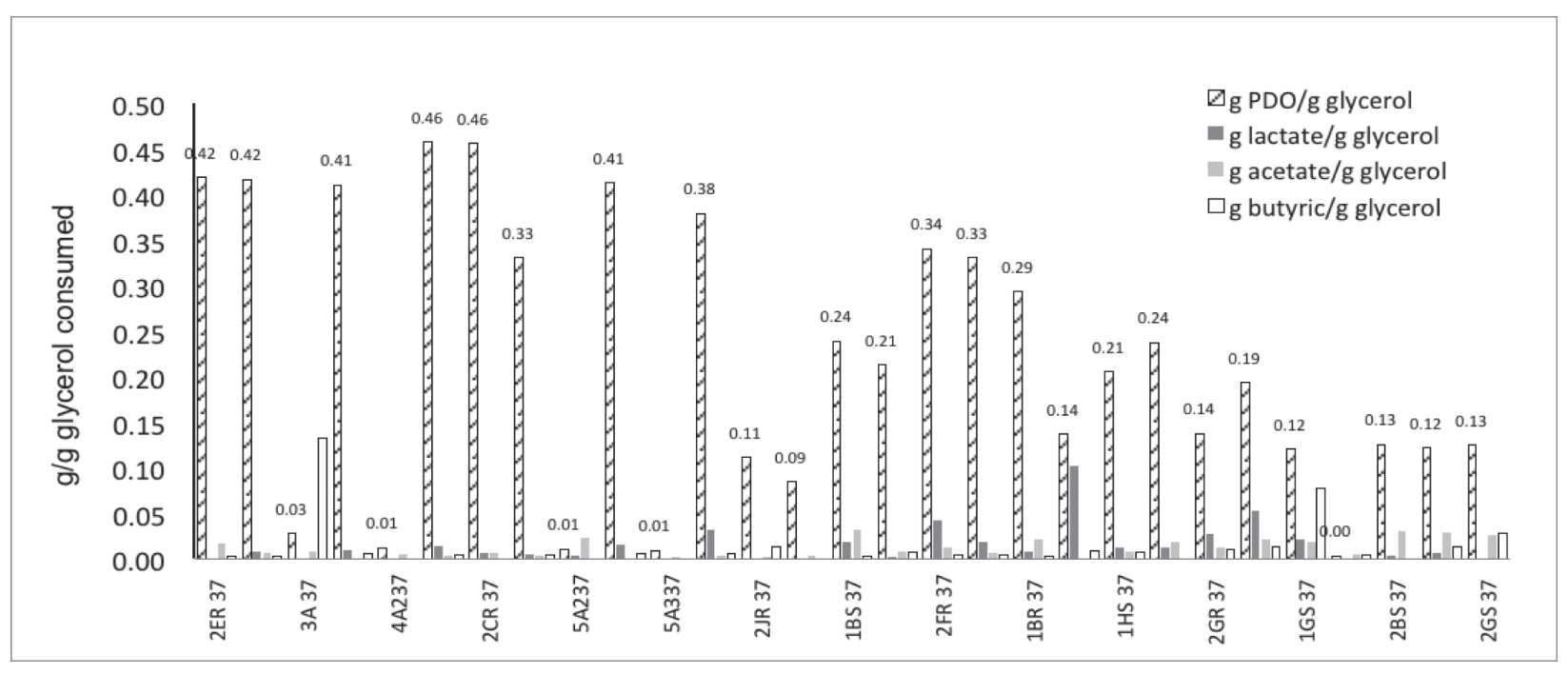

Figure 2. HPLC analysis of mixed cultures grown at $37^{\circ} \mathrm{C}$.

The yield of analysed fermentation products was calculated as $\mathrm{g}$ analysed product per $1 \mathrm{~g}$ of glycerol consumed.

Samples producing the highest amount of 1,3-PDO in the range of $0.38-0.46$ ( $\mathrm{g}$ per $\mathrm{g}$ of glycerol consumed) were selected for the next step of the study.

Seven mixed cultures named 2NR37, 2CR37, 2HS37, 2ER37, 2MS37, 2DR37, and 2MR37 were then cultured in 1 litre of the liquid medium containing $30{\mathrm{~g} \cdot \mathrm{l}^{-1}}^{\mathrm{glyc}-}$ erol. Single bacterial strains were isolated by consecutive culturing on solid, liquid and solid medium with glycerol. Flasks with fresh liquid medium containing glycerol were then inoculated with single colonies and after 4-7 days of growth the concentration of glycerol, 1,3-PDO and other metabolites was analysed (Table 1).

One of the eight isolated strains, 2MR375.1, did not ferment glycerol to $1,3-\mathrm{PDO}$, produced $0.56 \mathrm{~g}$ of propionate per $\mathrm{g}$ of glycerol which was much more than the other strains.

The highest 1,3-PDO production, in the range of $0.57-0.58 \mathrm{~g}$ per $1 \mathrm{~g}$ of glycerol consumed was obtained for strains 2CR371.5, 2NR371.5 and 2MS37.4. The strain 2NR371.5 produced $0.047 \mathrm{~g}$ of lactate whereas 2MS37.4 produced neither acetate nor butyrate. The three strains, 2CR371.5, 2NR371.5 and 2MS37.4 produced propionate in the range of $0.045-0.052 \mathrm{~g}$ (Table 1). None of the bacterial strains tested produced formic acid, 1-butanol or acetone. The strains 2MR375.1, 2ER371.1 and 2MS37.4 also produced up to $0.12 \mathrm{~g}$ of ethanol ( $\mathrm{Ta}$ ble 1). They produced fermenting gas which was a mixture of $\mathrm{CO}_{2}(98.5-99 \%)$ and $\mathrm{H}_{2}(1-1.5 \%)$.

Phylogenetic analysis was performed for six of the eight new isolates. Four of them were classified as C.butyricum, whereas 2ER371.1 showed the highest similarity to $C$. lituseburense and 2MR375.1 was classified as C. sartagoforme (Fig. 2). The analysis was not performed for strains 2MS37.4 and 2HS37.2. The sequenced fragments of $16 \mathrm{~S}$ rDNA of these six strains were submitted to the GenBank with the accession numbers JQ248565 to JQ248570.

\section{DISCUSSION}

Crude glycerol from biodiesel plants may be a good source of glycerol-fermenting microorganisms. It was found that supplementation with crude glycerol improves biogas production (Kolesárová et al., 2011). Bio- gas is produced in reactors under anaerobic conditions by a consortium of microorganisms including bacteria of the genus Clostridium (Dohrmann et al., 2011). All the bacterial strains we found in the environmental samples from biogas plants belong to this genus (Fig. 3).

The phylogenetic analysis was not performed for the 2MS37.4 and 2HS37.2 strains. However, comparing results of the fermentation with the other isolates and reference strains (Table 1) we can suppose that they are also C. butyricum strains.

The highest 1,3-PDO production in the range of $0.47-0.58 \mathrm{~g}$ per $1 \mathrm{~g}$ of glycerol consumed was observed for the $C$. butyricum strains. The yield of 1,3-PDO production was similar to the previously published results which were $0.52-0.55 \mathrm{~g}$ per $1 \mathrm{~g}$ of glycerol consumed (Chatzifragkou et al., 2011). It was higher but comparable to $0.368 \mathrm{~g}$ of the reference C. butyricum strain DSM2478 (Table 1). The higher yield to 1,3-PDO production by the newly isolated $C$. butyricum strains comparing with the reference DSM-2478 is probably connected with lactate level. In both these cases NADH is required so lactate production from glycerol is an alternative to 1,3-PDO production (Fig. 1). The reference $C$. butyricum strain produces the highest amount of lactate and conse-

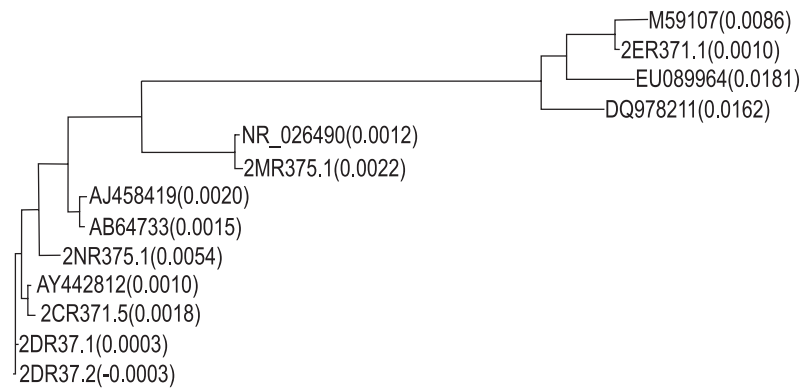

Figure 3. Phylogenetic analysis of newly isolated bacterial strains.

The analysis was based on the alignment of fragments of $16 \mathrm{~S}$ rDNA sequences. Values in parentheses following the molecule name represent the calculated distance between strains. M59107 - C. lituseburense; EU089964 - C. ruminatium strain LA1; DQ978211 - C. bifermentans strain HT2; NR 026490 - C. sartagoforme strain DSM 1292; AY442812 — C. butyricum; AJ458419C. diolis strain E5. 
quently the 1,3-PDO level is lower comparing with the new Clostridium strains.

Two of the strains, 2CR371.5 and 2MS37.4, did not produced lactate at all (Table 1).

Five of the six new C. butyricum strains produced butyrate as a by-product, similarly to the reference strain. The only $C$. butyricum strain which did not produce butyrate was 2MS37.4 (Table 1).

In contrast to the reference C. butyricum strain DSM2478, the newly isolated C. butyricum strains produced acetate as a by-product with the yield of $0.002-0.019 \mathrm{~g}$ per $g$ glycerol. On the other hand, they produced less propionate (Table 1).

The C. lituseburense strain 2ER371.1 which was isolated from the Hashoj biogas plant produced 1,3-PDO with a yield comparable to that of $C$. butyricum strains, but more acetate was present as a by-product (Table 1). Moreover, its growth was not as good as that of $C$. butyricum (data not shown).

C. sartagoforme $2 \mathrm{MR} 37.5$ as well as the reference strain C. sartagoforme DSM-1292 did not produced 1,3-PDO. In contrast to the reference $C$. sartagoforme strain, 2MR37.5 produced quite a large amount of propionate, an alternative of glycerol fermentation (Fig. 1, Table 1). We suggest that the glycerol fermentation to 1,3-PDO observed for the mixed culture 2MR37 (Fig. 2) was caused by other bacterial strain or strains we were unable to separate and cultivate.

According to our results, of the newly isolated bacterial strains 2NR371.5 is probably the best producer of 1,3-PDO. Just as 2MS37.4, it did not produce lactate, but it grew better than 2NR371.5. The anaerobic fermentation of glycerol by C. butyricum 2CR371.5 should now be optimized and performed in a larger scale. As the substrate for the fermentation we intend to test crude glycerol, a by-product of biodiesel production.

In the accompanying article (Dabrowski et al., 2012) we described construction of a recombinant $E$. coli strain producing 1,3-PDO from glycerol by introducing genes of the dha operon from C. butyricum 2CR371.5.

\section{Acknowledgements}

This work was financially supported by the $7^{\text {th }}$ Framework the European Union of, in the research area ENERGY-2007-3.3-02 — New uses for glycerine in biorefineries, project GLYFINERY (no. 213506).

\section{REFERENCES}

Altschul SF, Gish W, Miller W, Myers EW, Lipman DJ (1990) Basic local alignment search tool. J Mol Biol 215: 403-410.

Biebl H. (2001) Fermentation of glycerol by Clostridium pasteurianum batch and continuous culture studies. J Ind Microbiol Biotechnol 27: 18-26.

Boenigk R, Bowien S, Gottschalk G (1993) Fermentation of glycerol to 1,3-propanediol in continuous cultures of Citrobacter freundii. Appl Microbiol Biotechnol 38: 453-457.

Burkhard O, Grunwaldt E, Mahmoud O, Jennewein S (2009) Genome shuffling in Clostridium diolis DSM 15410 for improved 1,3-propanediol production. Appl Envir Microbiol 75: 7610-7616.

Chatzifragkou A, Papanikolaou S, Dietz D, Doulgeraki AI, Nychas GJ, Zeng AF (2011) Production of 1,3-propanediol by Clostridium butyricum growing on biodiesel-derived crude glycerol through a nonsterilized fermentation process. Appl Microbiol Biotechnol 91: 101-112.

Dabrock B, Bahl H, Gottschalk G (1992) Parameters affecting solvent production by Clostridium pasteurianum. Appl Environ Microbiol 58: 1233-1239.

Dąbrowski S, Pietrewicz-Kubicz D, Zabłotna E, Długołęcka A (2012) 1,3-propanediol production by Escherichia coli expressing genes of dha operon from Clostridium butyricum. Acta Biochim Pol 59: 000-000.

Dohrmann AB, Baumert S, Klingebiel L, Weiland P, Tebbe CC (2011) Bacterial community structure in experimental methanogenic bioreactors and search for pathogenic clostridia as community members. Appl Microbiol Biotechnol 89: 1991-2004.

Emptage M, Haynie SL, Laffend LA, Pucci JP, Whited G (2009) Process for the biological production of 1,3-propanediol with high titter. Pub: US 2009/0253192.

Eliot AC, Gatenby AA, Van Dyk TK (2011) Recombinant bacteria for producing glycerol and glycerol-derived products from sucrose. Pub: US 2011/0136190.

GlobalData (2010) Global Biodiesel Market Analysis and Forecasts to 2020 .

Gungormusler M, Gonen C, Ozdemir G, Azbar N (2010) 1,3-Propanediol production potential of Clostridium saccharobutylicum NRRL B-643. $N$ Biotechnol 27: 782-788.

Gupta A, Murarka A, Campbell P, Gonzales R (2009) Anaerobic fermentation of glycerol in Paenibacillus macerans: methabolic pathway and environmental determinants. Appl Envir Microbiol 75: 5871-5883.

Kolesárová N, Hutňan M, Bodík I, Spalková V (2011) Utilization of biodiesel by-products for biogas production. J Biomed Biotechnol 2011: 126798.

Liu H, Xu Y, Zheng Z, Liu D (2010) 1,3-Propanediol and its copolymers: research, development and industrialization. Biotechnol J 5: 1137-1148.

Mu Y, Teng H, Zhang D-J, Wang W, Xiu Z-L (2006) Microbial production of 1,3-propanediol by Klebsiella pneumoniae using crude glycerol from biodiesel preparations. Biotechnol Lett 28: 1755-1759.

Pasteris SE, Strasser de Saad AM (2009) Sugar-glycerol cofermentations by Lactobacillus hilgardii isolated from wine. I Agric Food Chem 57: 3853-3858.

Saitou M, Nei M (1987) The neighbor-joining method: a new method for reconstructing Guide Trees. Mol Biol Evol 4: 406-425.

Taconi KA, Venkataramanan KP, Johnson DT (2009) Growth and solvent production by Clostridium pasteurianum ATCC 6013 utilizing biodiesel-derived crude glycerol as the sole carbon source. Environ Prog Sust Energy 28: 100-110.

Weisburg WG, Barns SM, Pelletier DA, Lane DJ (1991) 16S ribosomal DNA amplification for phylogenetic study. I Bacteriol 173: 697-703.

Yazdani SS, Gonzalez R (2007) Anaerobic fermentation of glycerol: a path to economic viability for the biofuels industry. Curr Opin Biotechnol 18: 213-219. 